\title{
Cross-Functional Team Effectiveness Factors in Technological-Based Service Company: NSIAPAY
}

\author{
Muhammad Guntur Sulis Dwi Cahyo ${ }^{1, *}$ Riani Rachmawati ${ }^{2}$
}

\author{
${ }^{1}$ Universitas Indonesia \\ ${ }^{2}$ Universitas Indonesia \\ *Corresponding author.Email: ryandharmasaputro@gmail.com
}

\begin{abstract}
Due to the increase in market competition, companies in various industries are expected to be responsive to their dynamic environment. This paper aims to identify a cross-functional team's effective internal factors in a technologicalbased service company: NSIAPay to keep the value among employees while facing a fast-changing business world. A case study from NSIAPay helps characterize several factors that influenced cross-functional teams' effectiveness through shared leadership, cohesion, and internal team environment with its antecedent factors. This research used Structured Equation Modelling and was only carried out in financial technology company NSIAPay. It shows the influence of the internal team environment, cohesion, and shared leadership towards cross-functional team effectiveness. The higher the level of internal team environment and partially mediated by cohesion, it will positively influence CrossFunctional team effectiveness. The relationship between internal team environments mediated by shared leadership does not positively influence team effectiveness.
\end{abstract}

Keywords: Cross-Functional Team, Technological-Based Service Company, Dynamic Environment, FastChanging Business World, Internal Team Environment, Cohesion, Shared Leadership, Structured Equation Modeling.

\section{INTRODUCTION}

\subsection{Background}

Due to increasing market competition in the service industry that relies on a technological platform, building a responsive team to a dynamic business environment has become the essential factor in its development. The Minister of Communication and Information Indonesia Rudiantara had said that the digital economy in Indonesia would reach US $\$ 13$ billion or Rp. 1,831 trillion in 2020 . This would contribute to $11 \%$ of Indonesia's GDP [1]. The Institute for Development of Economics and Finance, together with Asosiasi Fintech Indonesia, made a study of the role of Financial Technology (Fintech) on the Indonesian economy using Input-Output (I-O) analysis, from the result it was found that the results of the development of Fintech in the country were able to increase the Gross Domestic Product (GDP) by Rp.25,97 trillion. To adapt to the fast-changing and massive growth of the technology and business competition among service companies, management needs to find ways to form more reacting quickly and positively.
When the company is surviving the external challenge, the company also has to keep developing and managing the value among the employees internally so that they can participate in the global market competition. A cross-functional team, which consists of persons from various functional fields in the company that works together to obtain a particular goal [2], is needed to contribute with a unique perspective in order to form an innovative team that is good at problem-solving [3]. As time goes by, companies have learned to cluster individuals, resources, and activities into processes, turning functional silos into cross-functionally relations that, through collaborating teamwork, can fulfill the demands of the market [4].

The concept of cross-functional integration has started from the need to construct the coordination between functional departments within a company that is essential to succeed in the market [5]. Cross-functional teams are utilized to accelerate the pace to market [6], develop a new product [7], and revamp the organization [8]. Cross-functional teams have competencies needed to 
accomplish the job without relying on others who are not part of the team [9].

Shared leadership is constructed by the overall team environment's dimensions, which consists of shared purpose, social support, and voice. Internal team environment enables shared leadership because they bond together to generate the type of team context that encourages team members' willingness to both offer influence of leadership and depends on the leadership of other team members [10].

Leadership is considered vital to enable team effectiveness, and some researchers put their opinions into an argument that it is the most crucial element. However, most previous research on team leadership has narrowly focused on the individual team leader, usually a manager external outside the team, and ruling out leadership provided by team members [10]. The complexity and ambiguity that is often experienced by the team make it impossible to successfully perform all essentials leadership purposes for a single external leader [11].

The structure of flatter organizational and the broad presence of teams that self-managed elaborate the requirement for leadership originating from within a team as the opposite of the one that was originating from a single individual appointed by hierarchy [11]. As a property emerged and resulted from leadership distribution, shared leadership influences across among team members. Shared leadership comes from individual team members of a team involved in activities that affect and influence the team and team members in areas related to support, motivation, and direction and within the series of interactions that individual in the team have with the other team members involving the responsibilities of leadership sharing and negotiation [10].

Earlier work on shared leadership has depended basically on totaling team members' appraisals of how much administration obligations are shared or certain practices are displayed within a team. Utilizing social network theory, the social network measurement approach is used to better capture these overall influence patterns.

Previous research on shared leadership has relied almost exclusively on performance ratings of team members and/or external leaders, a practice that expresses concern both about popular method variance and the ability to acquire an independent evaluation of the performance of a team [10]. Cohesion represents team members' commitment to each other and the team's aggregated task or purpose [12]. Cohesion is linked to the pursuit of common objectives and goals (i.e., shared purpose) [13].

NSIAPay is a technological-based service company that focuses on the financial industry. Established in 2007, NSIAPay is the first company that provides payment gateway and risk management in In- Indonesia. NSIAPay supports its customer in financial activities like selling, buying, transferring, and lending. With security licenses recognized internationally and supervised by Bank Indonesia, NSIAPay eases every customer transaction need. NSIApay is the pioneer of online payment services in Indonesia. Having more than $100 \mathrm{~K}$ Merchants and 2,5 M Users, NSIApay needs to be adaptive to the fast-changing business environment since it will affect the market needs and retain the acquired market share. By having many products like Remittance, NSIA Wallet, NSIA Merchant, risk management, and the payment gateway, forming a team that might selfdirected to innovate yet adding the company competitive advantages by being creative is needed to manage those products to keep them up to date to the advancement of the technology but still enhance the value of the company to answer customer needs and gain more competitive power in the market. With this condition, NSIApay needs to acquire the information and apply the latest technology to add more value to the company to capture the opportunity and fulfill the market needs since it changes with the current development.

\section{METHODS}

\subsection{Research model}

This research aims to investigate how internal factors enhance cross-functional team effectiveness through internal team environment, cohesion, and shared leadership. Therefore, this research model will refer to previous research. The research entitled "Crossfunctional team effectiveness: An Examination of an internal team environment, shared leadership, and cohesion influences" [12]. This model shows the internal team environment's relationship, which has three dimensions (shared purpose, social support, and voice) to cross-functional team effectiveness through the mediating influences of shared leadership and cohesion. The finding indicates that members are more likely to engage in shared leadership roles. Simultaneously, they recognize higher levels of shared purpose, social support and voice, and cross-functional team effectiveness are improved when individuals participate in shared leadership. When individuals perceive a constructive internal team environment, the cross-functional team's cohesion increases, thereby enhancing the level of crossfunctional team effectiveness [12]. Fig. 1. Show model internal team environment, and Table 1 . Show variables measurement \& indicator. 


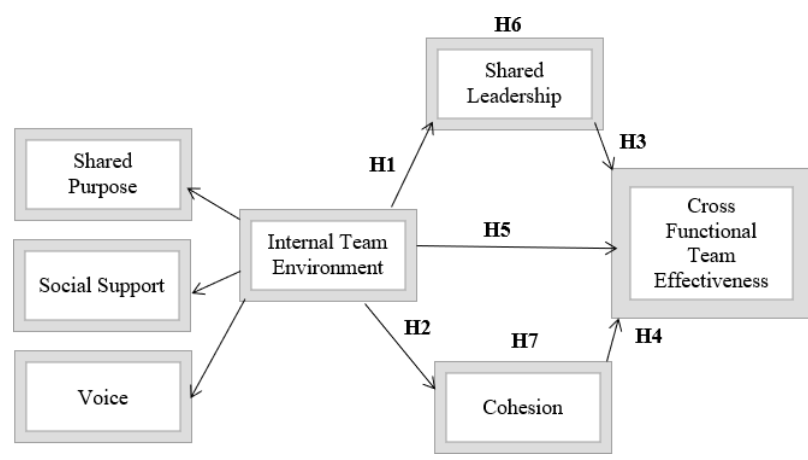

Figure 1. Model internal team environment

Table 1.Variables measurement \& Indicator

\begin{tabular}{|l|l|}
\hline \multicolumn{1}{|c|}{ Variable } & \multicolumn{1}{c|}{ Dimension } \\
\hline Internal team environment & Shared Leadership \\
\cline { 2 - 2 } & Social Support \\
\cline { 2 - 2 } & Voice \\
\hline Shared leadership & \\
\hline Cohesion & \\
\hline $\begin{array}{l}\text { Cross-functional team } \\
\text { effectiveness }\end{array}$ & \\
\hline
\end{tabular}

\subsection{Method of collecting data}

In collecting data, two data sources can be used, which are primary data and secondary. Primary data is the information obtained directly by the researcher, such as respondents of the questionnaire, related to variables that are being observed for a specific purpose of study, while secondary data is information collected from preexisting sources [14]. Primary data of this research is obtained through the distribution of the questionnaire and an interview with the management, more precisely vice president of process management of PT Nusa Satu Inti Artha (NSIAPay), to understand the problems and results of the research. Meanwhile, this research's secondary data comes from books, journals, reports and company guide, and relevant information from the internet.

The questionnaire was used to gather data through the list of questions to respondents related to the research subject and were involved in the cross-functional team. The respondent will be asked to answer the question that is considered the most relevant one. Those questions will be referring to the research's objective, the effective factor enhancing cross-functional team effectiveness. The items in the list of questions were answered on a Likert scale of six points. The scale indicator was 1 (Strongly disagree) to 6 (Strongly agree), averaging the scales' items to establish an aggregate mean of each variable. The items were coded to represent high levels of the observed construct. The questionnaire is also equipped with screening questions, which filter the respondent's response who is already involved in a crossfunctional team, so data that are not under the screening questions' condition will be considered as Not Valid responses and immediately discarded.
The questionnaire was distributed to the member of the cross-functional team in NSIAPay. The questionnaire was used to assess team member's perceptions of an internal team environment, shared leadership, cohesion, and team effectiveness. The questionnaire will be administered through a softcopy file word formatted.

\subsection{Data Analysis}

Data obtained from respondents will be analyzed and processed using Microsoft Excel 2016. Re- searcher used IBM SPSS Statistics 23 to test the reliability and validity of the items in the questionnaire.

\section{RESULTS AND DISCUSSION}

\subsection{Questionnaire result}

From the 174 distributed questionnaires, 138 respondents passed the screening and completed the questionnaire $(85.71 \%)$.

\subsection{Descriptive analysis}

Table 2. Descriptive analysis result

\begin{tabular}{|c|c|}
\hline Indicator & Mean \\
\hline SHARED1 & 4.70 \\
\hline SHARED2 & 4.67 \\
\hline SHARED3 & 4.65 \\
\hline SOCIAL1 & 4.63 \\
\hline SOCIAL2 & 4.25 \\
\hline SOCIAL3 & 4.43 \\
\hline VOICE1 & 4.41 \\
\hline VOICE2 & 4.60 \\
\hline VOICE3 & 4.78 \\
\hline VOICE4 & 4.33 \\
\hline LEADER1 & 4.36 \\
\hline LEADER2 & 4.43 \\
\hline LEADER3 & 4.27 \\
\hline LEADER4 & 4.12 \\
\hline LEADER5 & 4.61 \\
\hline LEADER6 & 4.38 \\
\hline LEADER7 & 4.30 \\
\hline LEADER8 & 4.23 \\
\hline LEADER9 & 4.20 \\
\hline LEADER10 & 4.52 \\
\hline COHESION1 & 4.54 \\
\hline COHESION2 & 4.57 \\
\hline COHESION3 & 4.56 \\
\hline COHESION4 & 4.48 \\
\hline COHESION5 & 4.68 \\
\hline OUT1 & 4.39 \\
\hline OUT2 & 4.39 \\
\hline OUT3 & 3.98 \\
\hline OUT4 & 4.42 \\
\hline OUT5 & 4.10 \\
\hline QUAL1 & 4.66 \\
\hline QUAL2 & 4.65 \\
\hline QUAL3 & 4.61 \\
\hline ORGPL1 & 4.55 \\
\hline ORGPL2 & 4.54 \\
\hline ORGPL3 & 4.05 \\
\hline ORGPL4 & 4.05 \\
\hline INTER1 & 4.71 \\
\hline INTER2 & 4.56 \\
\hline INTER4 & 4.64 \\
\hline
\end{tabular}




\begin{tabular}{|l|l|}
\hline VALUE1 & 4.06 \\
\hline VALUE2 & 4.63 \\
\hline VALUE3 & 4.13 \\
\hline ALL1 & 4.34 \\
\hline ALL2 & 4.50 \\
\hline ALL3 & 4.46 \\
\hline ALL4 & 4.51 \\
\hline
\end{tabular}

\subsection{Hypotheses test}

3.4. Table 3 show hypotheses result.

\begin{tabular}{|c|c|c|c|c|c|}
\hline $\begin{array}{c}\text { Cod } \\
\text { e }\end{array}$ & $\begin{array}{c}\text { Hypothese } \\
\text { s }\end{array}$ & $\begin{array}{c}\text { Estimat } \\
\mathrm{e}\end{array}$ & $\begin{array}{l}\text { CR } \\
\text { (T- }\end{array}$ & Code & $\begin{array}{c}\text { Hypothese } \\
\text { s }\end{array}$ \\
\hline H1 & $\begin{array}{ll}\text { LEA } & <- \\
-- & \\
\text { ENV } & \end{array}$ & 0.975 & $\begin{array}{l}8.57 \\
2\end{array}$ & $* * *$ & Accept \\
\hline $\mathrm{H} 2$ & $\begin{array}{ll}\text { CO } & <-- \\
\text { ENV }\end{array}$ & 0.975 & $\begin{array}{l}8.57 \\
2\end{array}$ & $* * *$ & Accept \\
\hline $\mathrm{H} 3$ & $\begin{array}{l}\text { CFT } \quad<--- \\
\text { LEA }\end{array}$ & 0.950 & $\begin{array}{l}9.60 \\
9\end{array}$ & $* * *$ & Reject \\
\hline $\mathrm{H} 4$ & $\begin{array}{l}\text { CFT }<--- \\
\text { CO }\end{array}$ & -0.088 & -0.29 & $\begin{array}{l}0.77 \\
2\end{array}$ & Accept \\
\hline H5 & $\begin{array}{l}\text { CFT } \\
<---E N V\end{array}$ & 0.317 & $\begin{array}{l}2.02 \\
7\end{array}$ & $\begin{array}{l}0.04 \\
3\end{array}$ & Accept \\
\hline H6 & $\begin{array}{l}\text { CFT <--- } \\
\text { LEA } \\
<--- \text { ENV }\end{array}$ & 0.765 & $\begin{array}{l}2.05 \\
4\end{array}$ & 0.04 & Reject \\
\hline $\mathrm{H} 7$ & $\begin{array}{l}\text { CFT } \\
<--- \\
\text { CO } \\
<---E N V\end{array}$ & -0.086 & & & Accept \\
\hline
\end{tabular}

For a hypothesis to be accepted, the CR (T-value) score must be above 1.645, while the p-value must be smaller than 0.05 . To find the model's indirect effect value, the researcher used a formulation from Sobel, an equivalent approach that calculates the indirect by multiplying two regression coefficients. From the 7 hypotheses, 2 hypotheses were rejected, which are H3 and H6.

\section{CONCLUSIONS}

From the test results, hypotheses that have been comprehensively described in the previous chapter on the combined model to analyze the relationships between precedents and variables of cross-functional team effectiveness, the researcher aims to elaborate the outcomes that can be concluded from the hypotheses of this study with additional insight from the literature study that has been done. It can be stated that: Findings from the hypotheses result show that internal team environment has a positive influence towards shared leadership. This relationship is proven by the $0.01 \mathrm{p}$ value, and with a t-value of $8.572 \mathrm{CR}$, the internal team environment has a $97.5 \%$ influence on shared leadership. Looking at the dimension that influence internal team environment, a dimension shows the most significant influence than others; SOCIAL (social support) influence
98.6\%. This dimension shows the importance of the team's supportive behavior, which is the effort to give emotional and psychological strength to one another by encouraging and recognizing team members' contribution and achievements. Findings from the hypotheses result show that the internal team environment positively influences cohesion. This relationship is proven by the $0.01 \mathrm{p}$-value, and with a tvalue of $9.609 \mathrm{CR}$, the internal team environment has a $95 \%$ influence on cohesion. It also shows that shared leadership does not have a positive influence on crossfunctional team effectiveness. This relationship is proven with $<0.05 \mathrm{p}$-value and with a t-value -0.29 . Shared leadership has an $8.8 \%$ influence on cross-functional team effectiveness. Looking at the indicators that influence shared leadership, LEADER5 (Team members collaborate in making decisions that affect this organization) shows the most significant influence than others with $86.4 \%$, compared to the other indicators. Findings from the hypotheses result show that cohesion has a positive influence on cross-functional team effectiveness. This relationship is proven with $<0.05 \mathrm{p}$ value and with t-value $2.027 \mathrm{CR}$ Cohesion has $31.7 \%$ influence on cross-functional team effectiveness.

While this finding is expected, this relationship is aligned with much previous research that has explained how cohesion directly influences cross-functional team effectiveness. Looking at the indicators that influence cohesion, COHES2 (members of my group work together as a team) shows the biggest influence than others with $86.6 \%$, compared to other indicators. Findings from the hypotheses result show that the internal team environment positively influences cross-functional team effectiveness. This relationship is proven with $<0.05 \mathrm{p}$ value and with t-value $2.054 \mathrm{CR}$ Internal team environment has $76.5 \%$ influence on cross-functional team effectiveness. While this finding is not aligned with the previous research of [12], that found there is no relationship between internal team environment and cross-functional team effectiveness. The dimension with the strongest influence on the internal team environment is social support with $98.6 \%$. This is an interesting finding as the influence is the biggest among all variables, compared to shared leadership and cohesion to- wards cross-functional team effectiveness. It can be concluded that the cross-functional team in NSIAPAY is more likely to shape the internal team environment through the sharing of information, objectives, and goals within the team. Findings from the hypotheses result show that the internal team environment does not positively influence cross-functional teams mediated by shared leadership. This relationship is proven with the negative influence of shared leadership mediating internal team environment and cross-functional team effectiveness. This indirect mediation effect influences $8.6 \%$ from an internal team environment to crossfunctional team effectiveness. This finding is not aligned 
with the previous result that shared leadership positively mediates the relationship between internal team environment and cross-functional team effectiveness. It may be concluded that a cross-functional team in NSIAPAY does not yet share the obligation of leadership within the team. They tend to believe on one single leader who facilitates the team comes from the team itself.

Findings from the hypotheses result show that the internal team environment has a positive influence towards cross-functional team effectiveness mediated by cohesion. This relationship is proven with the indirect value of $30.1 \%$ from an internal team environment to cross-functional team effectiveness via cohesion. This finding shows that there is statistical significance both on the direct effect and indirect effect of an internal team environment to cross-functional team effectiveness mediated by cohesion so that this is the relationship of partial mediation. The finding is aligned with the previous research that found positive influence from an internal team environment to cross-functional team effectiveness partially mediated by cohesion. In contrast, the previous research found that cohesion fully mediated the relationship between internal team environment and cross-functional team effectiveness.

\section{REFERENCES}

[1] Indonesian GDP growth slows further amid cooling investment, exports, The Jakarta Post, Dec 17, 2019. [Online]. Avaible: https://www.thejakartapost.com/news/2019/12/16/i ndonesian-gdp-growth-slows-further-amidcooling-investment-exports.html

[2] S.S. Webber, "Leadership and trust facilitating cross-functional team success," J. Management Development., vol. 21, no. 3, pp. 201-214, 2002, doi: 10.1108/02621710210420273.

[3] K. Lovelace, D.L. Shapiro, and L.R. Weingart, "Maximizing cross-functional new product teams' innovativeness and constraint adherence: A conflict communications perspective," Academy of management J., vol. 44, no. 4, pp.779-793, 2001.

[4] T. Galpin, R. Hilpirt, and B. Evans, "The connected enterprise: Beyond division of labor," J. Bus. Strategy, vol. 28, no. 2, pp. 38-47, 2007.

[5] E. A. De Oliveira, M.L. Pimenta, P. Hilletofth, and D. Eriksson, "Integration through cross-functional teams in a service company," European Business Review., 2016.

[6] Griffin, "The effect of project and process characteristics on product development cycle time," J. Mark. Res., vol. 34, no. 1, pp. 24-35, 1997.
[7] R. Bunduchi, "Implementing best practices to support creativity in NPD cross-functional teams," Int. J. Innov. Manag., vol. 13, no. 4, pp. 537-554, 2009.

[8] B. Tabrizi, Stanford Advanced Project Management Program. Web page. Retrieved from http://stanfordonline.stanford.edu/webinars/100721 apm.pdf, 2010

[9] K. Schwaber, and J. Sutherland, "The scrum guide," Scrum Alliance., vol. 21, no. 19, 2011.

[10] J. Carson, P. Tesluk, and J. Marrone, "Shared leadership in teams: an investigation of antecedent conditions and performance," Academy of Management J., pp. 1217- 1234, 2007.

[11]D.V. Day, P. Gronn, and E. Salas, "Leadership capacity in teams," The Leadership Quarterly., vol. 15, no. 6, pp. 857-880, 2014, doi: 10.1016/j.leaqua.2004.09.001.

[12] J. Daspit, C.J. Tillman, N.G. Boud, and V. Mckee, "Cross-functional team effectiveness: An examination of internal team environment, shared leadership, and cohesion influences," Team Performance Management., vol. 19, no. 1, pp. 34 56, 2013, doi: 10.1108/13527591311312088.

[13] D. C. Man and S. S. K. Lam, "The effects of job complexity and autonomy on cohesiveness in collectivistic and individualistic work groups: A cross-cultural analysis," J. Organ. Behav., vol. 24, no. 8, pp. 979-1001, 2003.

[14] U. Sekaran, and R. Bougie,. Research methods for business, 7th ed. John Wiley, 2016 